\title{
MECANiSMOS DE ABERTURA DE SUlCOS, INOCULAÇÃO E ADUBAÇÃo NITROGENADA EM FEIJOEIRO EM SISTEMA PLANTIO DIRETO (1)
}

\author{
FLÁVIO HIROSHI KANEKO $\left({ }^{2 *}\right)$; ORIVALDO ARF $\left({ }^{3}\right)$; DOUGLAS DE CASTILHO GITTI $\left({ }^{4}\right)$; \\ MARCELO VALENTINI ARF $\left({ }^{4}\right)$; JOÃO PAULO FERREIRA $\left({ }^{4}\right)$; SALATIÉR BUZETTI $\left({ }^{3}\right)$
}

\begin{abstract}
RESUMO
O feijão, juntamente com o arroz, constitui a base da alimentação dos brasileiros e para que possa ao mesmo tempo ser rentável ao produtor e acessível a toda população, é preciso desenvolver técnicas que elevem a produtividade com baixo custo. O objetivo deste trabalho foi estudar o efeito dos mecanismos de abertura de sulco para a deposição de fertilizantes (haste e disco duplo), da inoculação de sementes de feijão cultivar Pérola com estirpes de Rhizobium tropici com diferentes níveis de nitrogênio em cobertura (zero, 60, 120 e 180 $\mathrm{kg} \mathrm{ha}^{-1}$ ) no feijoeiro cultivado em sistema plantio direto. Utilizou-se o delineamento experimental em blocos casualizados em esquema fatorial $2 \times 2 \times 4$. O estudo foi desenvolvido no município de Selvíria (MS), em Latossolo Vermelho distrófico argiloso em 2006 e 2007. Conclui-se que o mecanismo de abertura do tipo haste promove a maior população final de plantas quando comparado ao uso do disco duplo desencontrado, incrementando a produtividade de grãos. A inoculação de sementes com Rhizobium tropici não interferiu no teor de $\mathrm{N}$ nas folhas bem como na produtividade de grãos. A adubação nitrogenada em cobertura proporcionou incrementos no teor de $\mathrm{N}$ nas folhas e na produtividade de grãos do feijoeiro de inverno.
\end{abstract}

Palavras-chave: Phaseolus vulgaris L., haste, disco duplo, fixação de nitrogênio, feijoeiro de inverno.

\section{ABSTRACT \\ FURROW OPENING MECHANISMS, INOCULATION OF SEEDS AND NITROGEN FERTILIZATION IN NO TILLAGE COMMON BEAN CROP}

Common bean and rice make the daily staple food of the Brazilian population. There is need to improve crop management techniques to increase yield of common bean leading to a decrease in the production costs to enable reasonable prices for consumers. The objective of this study was to evaluate the effects of furrow opening mechanisms for fertilizer deposition (double disk and knife coulter), inoculation of seeds with Rhizobium tropici and different levels of nitrogen fertilization at sidedressing ( Zero, 60, 120 e $180 \mathrm{~kg} \mathrm{ha}^{-1}$ ) on crop growth and yield, and leaf nitrogen (N) content. The experiment design was a randomized block in a factorial scheme $2 \times 2 \times 4$ and it was set up on a clayey Oxisol in Selviria, State of Mato Grosso do Sul, Brazil, in 206 and 2007. Opening knife coulter caused larger final plant population than double disk and led to an increase the grain yield. The seed inoculation with Rhizobium tropici did not interfere in the leaf $\mathrm{N}$ content and in the grain yield. The sidedressing nitrogen fertilization provided increments of leaf $\mathrm{N}$ content and in the grain yield of winter common bean crop.

Key words: Phaseolus vulgaris L., knife coulter, double disk, nitrogen fixation, winter common bean.

$\left(^{1}\right)$ Trabalho recebido para publicação em 3 de dezembro de 2008 e aceito em 22 de julho de 2009.

$\left(^{2}\right)$ Aluno de Pós Graduação, Faculdade de Engenharia - UNESP, Campus de Ilha Solteira, Caixa Postal 31, 15385-000 Ilha Solteira (SP). Bolsista FAPESP. E-mail: fhkaneko@hotmail.com $\left(^{*}\right)$ Autor correspondente.

$\left({ }^{3}\right)$ Faculdade de Engenharia, UNESP - Campus de Ilha Solteira. E-mail: arf@agr.feis.unesp.br; sbuzetti@agr.feis.unesp.br

$\left({ }^{4}\right)$ Alunos de Graduação em Agronomia, Faculdade de Engenharia - UNESP, Campus de Ilha Solteira, Bolsistas FAPESP. E-mail: gittidouglas@hotmail.com; marceoloarf@hotmail.com; ferreira_lobo@hotmail.com 


\section{INTRODUÇÃO}

O uso da irrigação permitiu o surgimento de nova época de cultivo para o feijoeiro, denominada "cultivo de inverno", com semeadura realizada de maio a julho (NASCIMENTO et al., 2004), em regiões sem risco de ocorrência de geada.

Pelo menor custo de operação, pelas melhorias do ponto de vista físico-químico e biológico do solo, além da fixação de carbono no solo (diminuindo problemas de aquecimento global pelo efeito estufa), o sistema plantio direto vem sendo cada vez mais adotado no Brasil, principalmente com grandes culturas tais como milho, soja e feijão. Esse sistema tem como base três pilares de sustentação: revolvimento do solo somente na linha de semeadura, manutenção da palhada sobre o solo e rotação de culturas.

De acordo com Silva et al. (2000), um dos entraves do sistema plantio direto é a dificuldade que muitos produtores têm em adequar as semeadorasadubadoras para distribuir uniformemente e em posição adequada as sementes e os fertilizantes.

Os mesmos autores citam que tal fato pode promover danos à germinação e ao desenvolvimento do sistema radicular. ARF et al. (2008) sugerem que para evitar tais problemas é necessário que as semeadoras-adubadoras tenham mecanismos eficientes de corte dos restos culturais e distribuição do fertilizante que proporcionem sua colocação em profundidade adequada.

CAMILO et al. (2004) estudaram o efeito de dois mecanismos de abertura de sulco para a deposição de fertilizantes (haste escarificadora e disco duplo) em Argissolo Vermelho-Amarelo com 44,51\% de umidade e observaram que nestas condições o uso do mecanismo rompedor do tipo haste proporcionou maior porcentagem de emergência de plântulas. LANDERS (1995) relata que as principais vantagens do uso do mecanismo do tipo haste (também chamado de facão ou "rompão") são: deposição do adubo na linha do disco cortador e abaixo da semente; realização de um pequeno preparo de solo na linha de semeadura, descompactando-o na camada superficial, o que favorece algumas culturas e penetração melhor em solo seco. O mesmo autor cita que, como desvantagem, a demanda por potência do trator é maior, 20 a $25 \mathrm{HP}$ a mais com oito linhas de semeadura; incorporação de parte da palha por jogar terra em cima; funcionamento irregular em solo úmido ou com palha espessa e tendência em deixar uma faixa sem palha sobre as linhas.

O desenvolvimento da lavoura de feijão e a produção de grãos dependem de um adequado suprimento de nutrientes. A associação de leguminosas com bactérias fixadoras de nitrogênio atmosférico é uma tecnologia capaz de substituir, pelo menos parcialmente, a adubação nitrogenada resultando em benefícios ao produtor. Para Pereira e Braidotti (2001) é possível que os melhoristas produzam cultivares de feijão responsivos à inoculação com bactérias do gênero Rhizobium com potencial para aumentar a fixação de $\mathrm{N}$ e a produtividade do feijoeiro. Araújo et al. (2007) relatam que a inoculação do feijoeiro é uma técnica difundida pela pesquisa, porém pouco utilizada pelos agricultores, devido a falta de consistência nos resultados das pesquisas em campo.

De acordo com Malavolta (1979), o nitrogênio é um dos nutrientes mais absorvidos pelo feijoeiro e quando aplicado na dose recomendada promove rápido crescimento, aumento da folhagem, aumento no teor de proteína nas sementes, alimenta os microrganismos do solo que decompõem a matéria orgânica, além de aumentar o teor de matéria seca. No entanto, quando fornecido em desequilíbrio, em relação aos outros elementos, pode atrasar o florescimento e a maturação e predispor as plantas ao ataque de doenças.

O objetivo deste trabalho foi avaliar a influência dos mecanismos de abertura de sulco para a deposição de fertilizantes, da inoculação de sementes com Rhizobium tropici e da adubação nitrogenada em cobertura no feijoeiro de inverno irrigado, em sistema plantio direto.

\section{MATERIAL E MÉTODOS}

O experimento foi realizado em área experimental localizada no município de Selvíria (MS), com coordenadas geográficas de $51^{\circ} 22^{\prime}$ de Longitude Oeste, $20^{\circ} 22^{\prime}$ de Latitude Sul, e altitude de 335 metros. O solo é do tipo Latossolo Vermelho distrófico argiloso, com precipitação pluvial média anual de $1370 \mathrm{~mm}$, temperatura média anual de 23,5 ${ }^{\circ} \mathrm{C}$ e a média anual de umidade relativa do ar entre $70 \%$ e $80 \%$.

O delineamento experimental foi o de blocos casualizados em um esquema fatorial $2 \times 2 \times 4$ com 16 tratamentos constituídos pela utilização de dois mecanismos de abertura de sulco para a deposição do fertilizante (haste escarificadora e disco duplo desencontrado); presença e ausência de inoculação de sementes com Rhizobium tropici e combinação de 4 níveis de nitrogênio em cobertura (zero, 60, 120 e $180 \mathrm{~kg} \mathrm{ha}^{-1}$ ). 
As parcelas foram constituídas por seis linhas de 6 metros de comprimento, sendo consideradas como área útil as quatro linhas centrais, desprezando-se 0,5 metro, em ambas as extremidades de cada linha.

A cultura foi instalada em 25 de maio de 2006 e 7 de maio de 2007 com irrigação por pivô central, sendo o milho a cultura antecessora, em sistema plantio direto. A dessecação da área foi efetuada com glifosato (1500 $\mathrm{g} \mathrm{ha}^{-1}$ de i.a). Utilizou-se a cultivar Pérola com plantas do tipo III e grãos tipo carioca, semeada mecanicamente no espaçamento de $0,50 \mathrm{~m}$ nas entrelinhas e 10 12 sementes por metro, em 2006, e no espaçamento de $0,45 \mathrm{~m}$ nas entrelinhas e $12-13$ sementes por metro, em 2007.

A inoculação foi realizada nas sementes com a dose recomendada pelo fabricante $(0,5 \mathrm{~L}$ p.c $/ 100 \mathrm{~kg}$ de sementes). As características químicas do solo antes da instalação da cultura eram as seguintes: $\mathrm{P}$ (resina) $=21 \mathrm{mg} \mathrm{dm}^{-3}, \mathrm{M} . \mathrm{O}=18 \mathrm{mg} \mathrm{dm}^{-}$ 3 , $\mathrm{pH}\left(\mathrm{CaCl}_{2}\right)=4,9, \mathrm{~K}, \mathrm{Ca}, \mathrm{Mg}, \mathrm{H}+\mathrm{Al}, \mathrm{Al}, \mathrm{SB}$ e CTC $=2,1 ; 28 ; 13 ; 35 ; 1 ; 44$ e $78 \mathrm{mmol}_{\mathrm{c}} \mathrm{dm}^{-3}$ respectivamente e $\mathrm{V}=56 \%$. Na semeadura utilizaram-se $250 \mathrm{~kg} \mathrm{ha}^{-1}$ da fórmula 04-30-10 e como fonte de $\mathrm{N}$ em cobertura utilizou-se uréia (seguida da aplicação de uma lâmina de água para minimizar perdas por volatilização). Foi realizada uma pulverização com o herbicida fluazifop-pbutyl + fomesafen $\left(160+200 \mathrm{~g} \mathrm{ha}^{-1}\right.$ do i.a) aos 20 dias após a emergência

As características avaliadas durante o desenvolvimento da cultura foram:

População de plantas: respectivamente na fase inicial de desenvolvimento da cultura e na ocasião da colheita, contou-se o número de plantas em duas linhas centrais de 4 metros e em seguida calculou-se o número de plantas por hectare.

Número de nódulos por planta: realizado em apenas uma repetição em 10 plantas por parcela na ocasião do florescimento. Retiraram-se as raízes das plantas e em seguida as mesmas foram lavadas sobre peneiras e os nódulos foram separados e contados.

Massa seca das plantas: por ocasião do florescimento pleno das plantas, coletaram-se 10 plantas em local predeterminado na área útil de cada parcela; em seguida, levou-se ao laboratório onde foram acondicionadas em sacos de papel devidamente identificados e colocados em estufa de ventilação forçada à temperatura média de 60 a $70^{\circ} \mathrm{C}$, até atingir massa em equilíbrio.
Teor de nitrogênio nas folhas: utilizaram-se as folhas das plantas coletadas em cada unidade experimental, durante o período de florescimento pleno. Após secagem em estufa com circulação forçada de ar 60 a $70{ }^{\circ} \mathrm{C}$, por 72 horas, as folhas foram moídas em moinho tipo Wiley e em seguida realizada a digestão sulfúrica, conforme método proposto por Malavolta et al. (1997).

Massa de cem grãos: obtida através da coleta ao acaso e pesagem de duas amostras de 100 grãos por parcela.

Produtividade de grãos: as plantas da área útil de cada parcela foram arrancadas e colocadas para secagem a pleno sol. Após a secagem, as plantas foram submetidas à trilhagem mecânica, os grãos pesados e os dados transformados em $\mathrm{kg} \mathrm{ha}^{-1}(13 \%$ base úmida).

\section{RESULTADOS E DISCUSSÃO}

A emergência das plantas ocorreu uniformemente nos dois anos de cultivo aos seis dias após a semeadura. O florescimento pleno foi registrado aos 42 e 43 dias após a emergência totalizando ciclo de 91 e 92 dias entre a semeadura até a colheita, respectivamente, para 2006 e 2007.

Não houve efeito significativo da interação mecanismos $x$ inoculação $x$ nitrogênio para as variáveis estudadas. Os dados referentes à população inicial, população final e número de nódulos por planta estão relacionados na tabela 1. Em relação à população inicial de plantas, observa-se que não houve efeito de nenhum tratamento isoladamente, tanto em 2006 quanto em 2007; entretanto, observa-se na tabela 2 que no primeiro ano de cultivo houve interação entre os mecanismos de abertura de sulco e a inoculação de sementes.

Verifica-se que houve melhoria na população inicial de plantas quando houve a combinação do uso das hastes e da inoculação de sementes com Rhizobium tropici. Fato difícil de ser explicado, haja vista que a formação da população inicial de plantas depende preponderantemente das reservas da semente, da umidade adequada do solo, do baixo impedimento da camada de solo que vai cobri-las e da ausência de ataque de patógenos e pragas de solo na fase inicial da cultura. Contudo, no segundo ano de cultivo, a melhor população inicial de plantas ocorreu na ausência de inoculação. 
Tabela 1. População inicial, população final e número de nódulos em feijoeiro de inverno cultivado sob dois mecanismos de abertura dos sulcos, inoculação de sementes e doses de nitrogênio em cobertura. Selvíria (MS), 2006 e 2007

\begin{tabular}{|c|c|c|c|c|c|c|c|}
\hline \multirow{2}{*}{\multicolumn{2}{|c|}{ Tratamentos }} & \multicolumn{2}{|c|}{ População inicial } & \multicolumn{2}{|c|}{ População final } & \multicolumn{2}{|c|}{ N. ${ }^{o}$ de nódulos planta ${ }^{-1}$} \\
\hline & & \multirow{2}{*}{2006} & 2007 & \multirow{2}{*}{\multicolumn{2}{|c|}{$\begin{array}{ll}2006 & 2007 \\
\end{array}$}} & \multirow[t]{2}{*}{2006} & \multirow[t]{2}{*}{2007} \\
\hline & & & pla & & & & \\
\hline & & & & canismos d & ra dos sul & & \\
\hline \multicolumn{2}{|c|}{ Disco duplo } & 141.438 & 242.187 & $118.259 \mathrm{~b}$ & $213.889 \mathrm{~b}$ & 71,5 & 33,2 \\
\hline \multirow{2}{*}{\multicolumn{2}{|c|}{ Haste }} & 146.125 & 241.232 & $141.091 \mathrm{a}$ & 225.608 a & 57,6 & 36,3 \\
\hline & & \multicolumn{6}{|c|}{ Inoculação de sementes } \\
\hline \multirow{2}{*}{\multicolumn{2}{|c|}{$\begin{array}{l}\text { Não inoculado } \\
\text { Inoculado }\end{array}$}} & 142.750 & $247.656 \mathrm{a}$ & 127.151 & $226.652 \mathrm{a}$ & 61,9 & 35,02 \\
\hline & & 144.812 & $235.764 \mathrm{~b}$ & 132.199 & $212.934 \mathrm{~b}$ & 67,1 & 34,5 \\
\hline \multicolumn{8}{|c|}{ Nitrogênio em cobertura $\left(\mathrm{kg} \mathrm{ha}^{-1}\right)$} \\
\hline \multicolumn{2}{|l|}{0} & 144.250 & 238.889 & 131.435 & 218.472 & 88,6 & 38,6 \\
\hline \multicolumn{2}{|l|}{60} & 144.750 & 239.063 & 127.684 & 219.323 & 79,3 & 32,55 \\
\hline \multicolumn{2}{|l|}{120} & 143.875 & 244.618 & 128.425 & 220.174 & 45,4 & 37,35 \\
\hline \multicolumn{2}{|l|}{180} & 142.250 & 244.270 & 131.157 & 221.024 & 44,8 & 30,55 \\
\hline \multirow{8}{*}{$\mathrm{F}$} & Mecanismos (M) & $3,94^{\mathrm{n} . \mathrm{s}}$ & $0,06^{\mathrm{ns}}$ & $42,25^{* *}$ & $9,58^{*}$ & - & - \\
\hline & Inoculação (I) & $0,76^{\text {n.s }}$ & $9,07^{*}$ & $2,21^{\mathrm{ns}}$ & $12,56^{*}$ & - & - \\
\hline & Nitrogênio (N) & $0,21^{\text {n.s }}$ & $0,64^{\mathrm{ns}}$ & $0,31^{\mathrm{ns}}$ & $0,59^{\mathrm{ns}}$ & - & - \\
\hline & $M \times I$ & $4,83^{*}$ & $0,30^{\mathrm{ns}}$ & $0,09^{\text {n.s }}$ & $2,09^{\mathrm{ns}}$ & - & - \\
\hline & $\mathrm{M} \times \mathrm{N}$ & $1,01^{\mathrm{ns}}$ & $1,60^{\mathrm{ns}}$ & $0,24^{\mathrm{ns}}$ & $0,48^{\mathrm{ns}}$ & - & - \\
\hline & $\mathrm{I} \times \mathrm{N}$ & $0,97^{\mathrm{ns}}$ & $0,53^{\mathrm{ns}}$ & $0,07^{\mathrm{ns}}$ & $1,27^{\mathrm{ns}}$ & - & - \\
\hline & Doses de $\mathrm{N}$ & & & & - & & \\
\hline & RL & $0,42^{\text {n.s }}$ & $1,511^{\mathrm{ns}}$ & $0,0001^{\mathrm{ns}}$ & $0,25^{\mathrm{ns}}$ & - & - \\
\hline \multirow{3}{*}{ DMS } & $\mathrm{RQ}$ & $0,20^{\text {n.s }}$ & $0,004^{\mathrm{ns}}$ & $0,92^{\mathrm{ns}}$ & $0,09^{\text {ns }}$ & - & - \\
\hline & Mecanismos & - & $6.824,15$ & 7.611,72 & - & - & \\
\hline & Inoculação & - & $7.937,65$ & - & $7.611,72$ & - & - \\
\hline \multicolumn{2}{|c|}{ CV( \%) } & 6,57 & 6,53 & 10,57 & 6,89 & - & - \\
\hline
\end{tabular}

${ }^{*}{ }^{* *}=$ significativos a $5 \%$ e $1 \%$ respectivamente pelo teste $\mathrm{F} .{ }^{\mathrm{ns}}=$ Não significativo. Letras diferentes indicam diferença significativa a $5 \%$ pelo teste de Tukey.

Tabela 2. Desdobramento das interações significativas da análise de variância referente à população inicial de plantas. Selvíria (MS), 2006

\begin{tabular}{lcr}
\hline Mecanismos de abertura do sulco & \multicolumn{2}{c}{ Inoculação de Sementes } \\
\cline { 2 - 3 } & Não inoculado & Inoculado \\
\hline Disco duplo & 143.000 & 139.875 b \\
Haste & $142.500 \mathrm{~B}$ & 149.750 a A \\
\hline
\end{tabular}

DMS Mecanismos dentro de inoculação $-6.712,58$

Inoculação dentro de mecanismos - 6.712,58

Letras diferentes, minúsculas nas colunas e maiúsculas nas linhas, indicam diferença significativa pelo teste de Tukey a $5 \%$. 
CAmilo et al. (2004) estudaram o efeito dos mecanismos de abertura de sulco associados à velocidade da semeadora em plantio direto e concluíram que as hastes proporcionaram maior porcentagem e maior índice de velocidade de emergência de plântulas, sendo fundamental para a formação de adequada população inicial de plantas. ROMANINI JUNIOR (2004) avaliou o efeito da inoculação de sementes e aplicação de nitrogênio no feijoeiro em sistema plantio direto e concluiu que a população inicial de plantas não foi influenciada pela inoculação e pelo manejo do $\mathrm{N}$ na semeadura e em cobertura.

Para a população final de plantas verificouse, nos dois anos de cultivo, que o mecanismo de abertura de sulco do tipo haste incrementou significativamente esta variável em relação ao disco duplo. Arf et al. (2008), trabalhando também em Latossolo Vermelho-Escuro argiloso verificaram resultados semelhantes em dois anos de cultivo. Em relação à inoculação de sementes, no primeiro ano não houve diferenças significativas, porém em 2007 a inoculação de sementes com Rhizobium tropici proporcionou menor população final de plantas. Não houve efeito da adubação nitrogenada em cobertura para esta variável.

Não foi efetuada análise estatística para a variável número de nódulos por planta, pois o objetivo desta avaliação foi verificar a presença ou ausência de estirpes nativas de bactérias simbióticas. Assim, os resultados indicam a presença de estirpes nativas na área de cultivo, entretanto, em 2006, a presença de estirpes nativas foi maior que em 2007.

Os dados referentes à massa seca das plantas, teor de $\mathrm{N}$ nas folhas e número de vagens por planta estão relacionados na tabela 3 . A massa seca das plantas não foi influenciada pelos mecanismos de abertura de sulco no primeiro ano de cultivo, entretanto, no segundo ano o uso do disco duplo proporcionou maior valor para esta variável. Sendo a população final de plantas menor com o uso do disco duplo, é de se esperar que a massa seca das plantas seja maior com o uso deste mecanismo, uma vez que a cultivar utilizada é de hábito de crescimento indeterminado, com capacidade de produzir mais ramas para preencher os espaços vazios, aumentando desta forma a massa seca das plantas. Contudo ArF et al. (2008) estudando a influência dos mecanismos de abertura de sulco para a deposição de fertilizantes e da adubação nitrogenada no feijoeiro, não observaram diferença significativa da massa seca das plantas para a mesma cultivar (Pérola) entre os mecanismos de abertura de sulco.

Em relação à inoculação de sementes, é possível observar que não houve influência nos dois anos de cultivo para a massa seca das plantas. A adubação nitrogenada em cobertura incrementou esta variável até a dose de $114,62 \mathrm{~kg} \mathrm{ha}^{-1}$ de $\mathrm{N}$ em 2006, porém, em 2007, este fato não se repetiu.

RodRIGUEs et al. (1994) estudaram o efeito da inoculação, calagem e adubação em mucuna-preta e feijão de porco e não verificaram diferenças para a produção de massa seca nas parcelas que receberam inoculação com bactérias do gênero Rhizobium. NASCimento et al. (2004) estudaram a resposta do feijoeiro à adubação nitrogenada em cobertura e de molibdênio via foliar em diferentes fases fenológicas do feijoeiro e não observaram efeito significativo dos tratamentos para a massa seca das plantas.

Para o teor de $\mathrm{N}$ nas folhas não houve influência dos mecanismos de abertura de sulco bem como da inoculação de sementes com Rhizobium tropici nos dois anos de cultivo. Entretanto, os valores estão dentro da faixa de teores adequados (30 a $\left.50 \mathrm{~g} \mathrm{~kg}^{-1}\right)$, de acordo com Ambrosano et al. (1997). Houve influência das doses de $\mathrm{N}$ em cobertura para a variável em questão, tanto em 2006 como em 2007. No primeiro ano, a resposta foi linear e no segundo ano, quadrática, sendo a máxima resposta obtida com a dose de $152 \mathrm{~kg} \mathrm{ha}^{-1}$ de $\mathrm{N}$.

Houve interações significativas para o número de vagens por planta, tanto em 2006 quanto em 2007. Em 2006, a inoculação das sementes com Rhizobium tropici associada com o mecanismo do tipo disco duplo promoveram maior valor para esta variável (Tabela 4).

Em 2007, a interação para o número de vagens por planta foi entre os mecanismos de abertura de sulco e as doses de $\mathrm{N}$ em cobertura e o desdobramento está apresentado na tabela 5 . Observa-se que quando se utilizou $180 \mathrm{~kg} \mathrm{ha}^{-1}$ de N em cobertura o mecanismo do tipo haste promoveu maior número de vagens por planta. Houve resposta significativa também para doses de $\mathrm{N}$ em cobertura, quando se utilizaram as hastes como mecanismo de abertura de sulco. Arf et al. (2008) não verificaram resposta dos mecanismos de abertura de sulco para a deposição de fertilizantes em relação ao número de vagens por planta; os mesmos autores, porém, verificaram incremento linear para esta variável quando se aumentaram as doses de $\mathrm{N}$ em cobertura até a dose de $125 \mathrm{~kg} \mathrm{ha}^{-1}$. ARAújo et al. (2007) não observaram efeito da inoculação para o número de vagens por planta. Soratto et al. (2001) e Alvarez et al. (2005) observaram resultados positivos para o número de vagens por planta quando se elevaram as doses de $\mathrm{N}$.

Os dados referente a massa de 100 grãos e a produtividade de grãos estão listados na tabela 6 . 
Tabela 3. Massa seca de plantas, teor de $\mathrm{N}$ nas folhas e número de vagens por planta em feijoeiro de inverno cultivado sob dois mecanismos de abertura dos sulcos, inoculação de sementes e doses de nitrogênio em cobertura. Selvíria (MS), 2006 e 2007

\begin{tabular}{|c|c|c|c|c|c|c|}
\hline \multirow{2}{*}{ Tratamentos } & \multicolumn{2}{|c|}{ Massa seca das plantas } & \multicolumn{2}{|c|}{ Teor de $\mathrm{N}$ nas folhas } & \multicolumn{2}{|c|}{$\mathrm{N}^{\circ}$ de vagens planta ${ }^{-1}$} \\
\hline & 2006 & 2007 & 2006 & 2007 & 2006 & 2007 \\
\hline
\end{tabular}

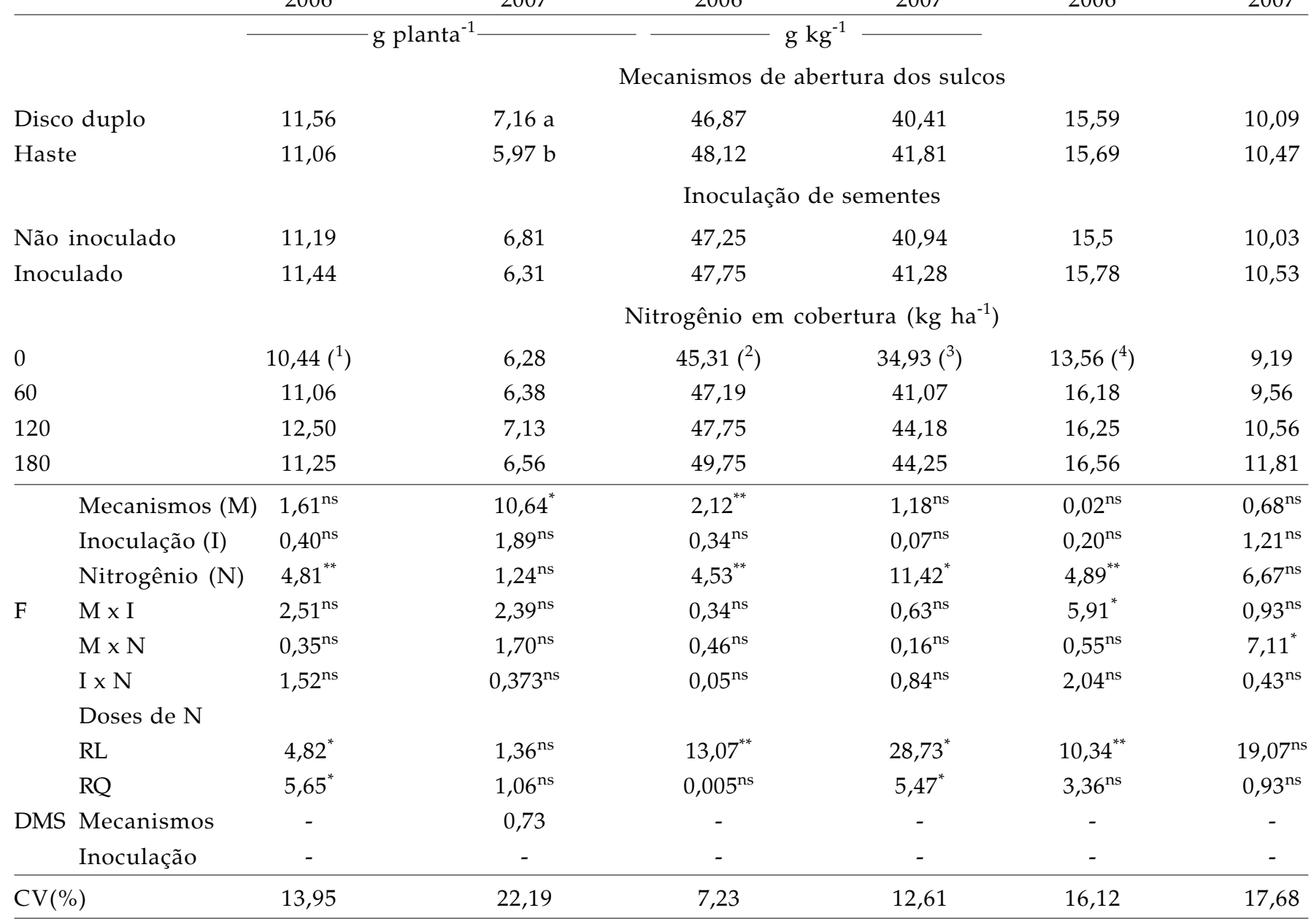

${ }^{*} \mathrm{e}^{* *}=$ significativos a 5 e $1 \%$ respectivamente pelo teste $\mathrm{F} .{ }^{\mathrm{ns}}=$ Não significativo. Letras diferentes indicam diferença significativa a $5 \%$ pelo teste de Tukey. $\left({ }^{1}\right) y=10,2625+0,0298 x-0,00013 x^{2} \quad\left(R^{2}=0,73\right) .\left({ }^{2}\right) y=45,4187+0,0231 x\left(R^{2}=0,96\right) .\left({ }^{3}\right) y=34,934+0,128 x-0,00042 x^{2}\left(R^{2}\right.$ $=0,99) \cdot\left({ }^{4}\right) \mathrm{y}=14,2812+0,0151 \times\left(\mathrm{R}^{2}=0,33\right)$.

Tabela 4. Desdobramento das interações significativas da análise de variância referente ao número de vagens por planta. Selvíria (MS), 2006

\begin{tabular}{lcc}
\hline Mecanismos de abertura do sulco & Não inoculado & Inoculação de sementes \\
\cline { 2 - 3 } Disco duplo & $14,69 \mathrm{~B}$ & Inoculado \\
Haste & 16,31 & $16,50 \mathrm{~A}$ \\
\hline DMS & Mecanismos dentro de inoculação - 1,79 \\
& Inoculação dentro de mecanismos - 1,79 \\
\hline
\end{tabular}

Letras diferentes, minúsculas nas colunas e maiúsculas nas linhas, indicam diferença significativa pelo teste de Tukey a $5 \%$. 
Tabela 5. Desdobramento da interação significativa da análise de variância referente ao número de vagens por planta Selvíria (MS), 2007

\begin{tabular}{|c|c|c|c|c|c|c|}
\hline \multirow{2}{*}{$\begin{array}{l}\text { Mecanismos } \\
\text { de abertura de sulco }\end{array}$} & \multicolumn{4}{|c|}{ Doses de $\mathrm{N}$} & \multirow{2}{*}{$\mathrm{R}^{2}$} & \multirow{2}{*}{$(\%)$} \\
\hline & 0 & 60 & 120 & 180 & & \\
\hline & \multicolumn{6}{|c|}{$\overline{\mathrm{kg} \mathrm{ha}^{-1} \longrightarrow}$} \\
\hline Disco duplo & 9,75 & 9,5 & 11,25 & $9,87 \mathrm{~b}$ & ns & - \\
\hline Haste & 8,63 & 9,62 & 9,87 & $13,75 \mathrm{a}$ & $\mathrm{L}^{*}$ & $80,15^{1}$ \\
\hline DMS & - & - & - & 1,83 & - & - \\
\hline
\end{tabular}

ns = não significativo a $5 \%$ de probabilidade pelo teste de regressão. Letras diferentes indicam diferença significativa a $5 \%$ pelo teste de Tukey. $L^{*}$ : Regressão Linear significativa a $5 \%$ de probabilidade. ${ }^{1} \mathrm{y}=8,125+0,0260 \mathrm{x}$.

Tabela 6. Massa de 100 grãos e produtividade de grãos em feijoeiro de inverno cultivado sob dois mecanismos de abertura dos sulcos, inoculação de sementes e doses de nitrogênio em cobertura. Selvíria (MS), 2006 e 2007

\begin{tabular}{|c|c|c|c|c|c|}
\hline \multirow{2}{*}{\multicolumn{2}{|c|}{ Tratamentos }} & \multicolumn{2}{|c|}{ Massa de 100 grãos } & \multicolumn{2}{|c|}{ Produtividade } \\
\hline & & \multirow[t]{3}{*}{2006} & \multirow{2}{*}{2007} & \multirow{2}{*}{\multicolumn{2}{|c|}{$2006 \quad \mathrm{~kg} \mathrm{ha}^{-1}$}} \\
\hline & & & & & \\
\hline & & & ecanismo & a dos sulc & \\
\hline \multicolumn{2}{|c|}{ Disco duplo } & 23,31 & 27,5 & 1.914 & $2.113 \mathrm{~b}$ \\
\hline \multicolumn{2}{|c|}{ Haste } & 22,87 & 27,75 & 1.832 & $2.338 \mathrm{a}$ \\
\hline & & \multicolumn{4}{|c|}{ Inoculação de sementes } \\
\hline \multicolumn{2}{|c|}{ Não inoculado } & 22,94 & 27,75 & 1.842 & 2.256 \\
\hline \multirow{2}{*}{\multicolumn{2}{|c|}{ Inoculado }} & 23,25 & 27,5 & 1.904 & 2.195 \\
\hline & & \multicolumn{4}{|c|}{ Nitrogênio em cobertura $\left(\mathrm{kg} \mathrm{ha} \mathrm{h}^{-1}\right)$} \\
\hline \multicolumn{2}{|l|}{0} & 23,25 & $26,80\left({ }^{1}\right)$ & $1.776\left(^{2}\right)$ & $1.894\left({ }^{3}\right)$ \\
\hline \multicolumn{2}{|l|}{60} & 23,31 & 27,35 & 1.803 & 2.115 \\
\hline \multicolumn{2}{|l|}{120} & 22,81 & 27,9 & 1.934 & 2.336 \\
\hline \multicolumn{2}{|l|}{180} & 23 & 28,45 & 1.977 & 2.557 \\
\hline \multirow{8}{*}{$\mathrm{F}$} & Mecanismos (M) & $2,67^{\mathrm{ns}}$ & $0,96^{\mathrm{ns}}$ & $1,92^{\mathrm{ns}}$ & $10,18^{*}$ \\
\hline & Inoculação (I) & $1,36^{\mathrm{ns}}$ & $0,96^{\mathrm{ns}}$ & $1,08^{\mathrm{ns}}$ & $0,76^{\text {n.s }}$ \\
\hline & Nitrogênio (N) & $0,74^{\mathrm{ns}}$ & $7,80^{*}$ & $2,75^{*}$ & $16,76^{*}$ \\
\hline & $M \times I$ & $0,06^{\mathrm{ns}}$ & $0,24^{\mathrm{ns}}$ & $0,002^{\text {ns }}$ & $1,05^{\mathrm{n} \cdot \mathrm{s}}$ \\
\hline & $\mathrm{M} \times \mathrm{N}$ & $0,82^{\mathrm{ns}}$ & $1,27^{\mathrm{ns}}$ & $0,78^{\mathrm{ns}}$ & $0,15^{\text {n.s }}$ \\
\hline & $\mathrm{I} \times \mathrm{N}$ & $0,74^{\mathrm{ns}}$ & $0,80^{\mathrm{ns}}$ & $0,54^{\mathrm{ns}}$ & $1,15^{\text {n.s }}$ \\
\hline & Doses de $\mathrm{N}$ & & & & \\
\hline & RL & $1,09^{n . s}$ & $23,12^{*}$ & $7,70^{* *}$ & $49,30^{*}$ \\
\hline \multirow{3}{*}{ DMS } & RQ & $0,05^{\mathrm{n} . \mathrm{s}}$ & $0,24^{\mathrm{ns}}$ & $0,02^{\mathrm{ns}}$ & $0,99^{\text {n.s }}$ \\
\hline & Mecanismos & - & - & - & 141,58 \\
\hline & Inoculação & - & - & - & - \\
\hline \multicolumn{2}{|c|}{$\mathrm{CV}(\%)$} & 4,64 & 3,7 & 12,64 & 12,66 \\
\hline
\end{tabular}

$\left({ }^{1}\right) \mathrm{y}=26,80+0,00916 \mathrm{x}\left(\mathrm{R}^{2}=98,78 \%\right) \cdot\left({ }^{2}\right) \mathrm{y}=1762,6+1,2241 \mathrm{x}\left(\mathrm{R}^{2}=93,39 \%\right) .\left({ }^{3}\right) \mathrm{y}=1894,05+3,6852 \mathrm{x}\left(\mathrm{R}^{2}=98,02 \%\right) .{ }^{*} \mathrm{e}^{* *}=$ significativos a 5 e $1 \%$ respectivamente pelo teste F. ${ }^{\text {ns }}=$ Não significativo. Letras diferentes indicam diferença significativa a $5 \%$ pelo teste de Tukey. 
A massa de cem grãos não foi influenciada pelos mecanismos de abertura de sulco bem como pela inoculação nos dois anos de cultivo; todavia, em 2007, a adubação nitrogenada em cobertura aumentou linearmente a massa de cem grãos. ARF et al. (2008) citam que a massa de cem grãos está mais relacionada com as características genéticas da cultivar utilizada (Tabela 6)

Em relação à produtividade de grãos, observase que não houve efeito significativo dos mecanismos de abertura de sulco em 2006, porém, em 2007, o uso das hastes proporcionou maiores ganhos em relação ao disco duplo (Tabela 6). Arf et al. (2008) constataram resultados favoráveis ao uso do mecanismo do tipo haste para a produtividade de grãos. Os autores verificaram em dois anos de cultivo que houve aumento significativo na produtividade de grãos, quando foram utilizadas as hastes como mecanismo de abertura de sulco para a deposição de fertilizantes. ROMANINI JÚNIOR (2004) notou respostas significativas na inoculação com bactérias fixadoras de $\mathrm{N}$ para a produtividade de grãos no feijoeiro.

A resposta do feijoeiro à adubação nitrogenada em cobertura foi linear e positiva nos dois anos de cultivo, indicando que no solo em questão existe potencial de resposta às doses maiores que as empregadas neste trabalho. Fernandes et al. (2005), para a cultivar IAC Carioca Eté, concluíram que doses crescentes de $\mathrm{N}$ em cobertura aumentaram a produtividade de grãos. Silveira et al. (2005) estudaram o efeito da adubação nitrogenada em feijoeiro cultivado em sistema plantio direto sob sucessão de culturas e concluíram que a produtividade de grãos se ajustou à função quadrática em resposta à adubação nitrogenada na palhada de milheto e guandu. Porém, NASCIMENTO et al. (2004) não observaram respostas à adubação nitrogenada.

\section{CONCLUSÕES}

1. O mecanismo de abertura de sulco para a distribuição de fertilizantes do tipo haste escarificadora promove maior população final de plantas, quando comparadas ao uso do disco duplo desencontrado, podendo com isso favorecer o aumento da produtividade de grãos;

2. A inoculação de sementes com Rhizobium tropici não interfere no teor de $\mathrm{N}$ nas folhas bem como na produtividade de grãos;

3. A adubação nitrogenada em cobertura proporciona incrementos no teor de $\mathrm{N}$ nas folhas e na produtividade de grãos do feijoeiro de inverno.

\section{AGRADECIMENTOS}

Os autores agradecem à FAPESP e ao $\mathrm{CNPq}$ pelo apoio financeiro, e aos funcionários da Fazenda de Ensino, Pesquisa e Extensão (FEPE) da Faculdade de Engenharia de Ilha Solteira (FEIS/UNESP).

\section{REFERÊNCIAS}

ALVAREZ, A.C.C.; ARF, O.; ALVAREZ, R.C.F.; PEREIRA, J.C.R. Resposta do feijoeiro à aplicação de doses e fontes de nitrogênio em cobertura no sistema de plantio direto. Acta Scientiarum Agronomy, v.27, p.69-75. 2005.

AMBROSANO, E.J.;TANAKA, R.T.; MASCARENHAS, H.A.A.; RAIJ.B. V.; QUAGGIO, J.A.; CANTARELLA, H. Leguminosas e oleaginosas. In: RAIJ, B.V.; CANTARELLA, H.; QUAGGIO, J.A.; FURLANI, A.M.C (Ed.). Recomendações de adubação e calagem para o Estado de São Paulo. 2.ed.rev. Campinas: IAC, 1997. p.189-203. (Boletim técnico, 100)

ARAÚJO, F.F.; CARMONA, F.G.; TIRITAN, C.S.; CRESTE, J.E. Fixação biológica de $\mathrm{N}_{2}$ no feijoeiro submetido a dosagens de inoculante e tratamento químico na semente comparado à adubação nitrogenada. Acta Scientiarum Agronomy, v.29, p. 535-540, 2007.

ARF, O.; AFONSO, R.J.; ROMANINI JUNIOR, A.; SILVA, M.G.; BUZETTI, S. Mecanismos de abertura do sulco e adubação nitrogenada no cultivo do feijoeiro em sistema plantio direto. Bragantia, v. 67, p.499-506, 2008.

CAMILO, A.J.; FERNANDES H.C.; MODOLO, A.J.; RESENDE, R.C. Influencia de mecanismos rompedores e velocidade de trabalho no desempenho de semeadora-adubadora de plantio direto do feijão. Engenharia na Agricultura, v.12, p.203-211. 2004.

FERNANDES, F.A.; ARF, O.; BINOTTI, F.F.S.; ROMANINI JUNIOR, A.; SÁ, M.E.; BUZETTI, S.; RODRIGUES, R.A.F. Molibdênio foliar e nitrogênio em feijoeiro cultivado no sistema plantio direto. Acta Scentiarum Agronomy, v. 27, p. 07-15. 2005.

LANDERS, J.N. Fascículo de experiências de plantio direto no cerrado.Goiânia: A.P.D.C., 261p. 1995.

MALAVOLTA, E.; VITTI, G.C.; OLIVEIRA, S.A. Avaliação do estado nutricional das plantas: princípios e aplicações. Piracicaba: Potafós, 1997. 319 p.

MALAVOLTA. E. Adubos nitrogenados. In: Abc da adubação. 4.ed. São Paulo: Agronômica Ceres, 1979. p.25-39.

NASCIMENTO, M.S.; ARF, O.; SILVA, M.G. Resposta do feijoeiro à adubação de nitorgênio em cobertura e molibdênio via foliar. Acta Scientiarum. Agronomy, v.26, p.153-159. 2004.

PEREIRA, A.A.; BRAIDOTTI, W. Comparação de métodos de melhoramento de feijão (Phaseolus vulgaris L.) para o incremento da fixação simbiótica de nitrogênio. Pesquisa Agropecuária Tropical, v.31, p.15-21, 2001. 
RODRIGUES, E.F.G.; POLLI, H.; EIRA, P.A. Inoculação, calagem e adubação para mucuna-preta e feijão-de-porco num solo Podzólico Vermelho-Amarelo. Pesquisa Agropecuária Brasileira, v.29, p.807-814.1994.

ROMANINI JUNIOR, A. Inoculação de sementes e aplicação de nitrogênio no desenvolvimento do feijão em sistema plantio direto. 2004, 59p. Monografia (Trabalho de Graduação) - FE/UNESP, Ilha Solteira.

SILVA, J.G.; KLUTHCOUSCKI, J.; SILVEIRA, P.M. Desenvolvimento de uma semeadora-adubadora no estabelecimento e na produtividade da cultura do milho sob plantio direto. Scentia Agrícola, v. 57, p.7-12, 2000.

SILVEIRA, P.M.; BRAZ, A.J.B.P.; KLIEMANN, H.J.; ZIMMERMANN, F.J.P. Adubação nitrogenada no feijoeiro cultivado sob plantio direto em sucessão de culturas. Pesquisa Agropecuária Brasileira, v.40, p.377-381. 2005.

SORATTO, R.P.; SILVA, T.R.B.; ARF, O.; CARVALHO, M.A.C. Níveis e épocas de aplicação de nitrogênio em cobertura no feijoeiro irrigado em plantio direto. Cultura Agronômica, v.10, p.89-99. 2001. 